\title{
Recent Trends in Load Forecasting Technology for the Operation Optimization of Distributed Energy System
}

\author{
Pengwei Su, Xue Tian, Yan Wang, Shuai Deng *, Jun Zhao, Qingsong An and Yongzhen Wang \\ Key Laboratory of Efficient Utilization of Low and Medium Grade Energy, Ministry of Education, \\ Tianjin University, Tianjin 300350, China; supengwei86@163.com (P.S.); snowfieldtian@126.com (X.T.); \\ wangyan_930@tju.edu.cn (Y.W.); zhaojun@tju.edu.cn (J.Z.); anqingsong@tju.edu.cn (Q.A.); \\ wyz80hou@tju.edu.cn (Y.W.) \\ * Correspondence: sdeng@tju.edu.cn; Tel.: +86-022-2740-4188
}

Received: 20 June 2017; Accepted: 27 August 2017; Published: 31 August 2017

\begin{abstract}
The introduction of renewable resources into the distributed energy system has challenged the operation optimization of the distributed energy system. Integration of new technologies and diversified characteristics on the demand side has exerted a great influence on the distributed energy system. In this paper, by way of literature review, first, the topological structure and the mathematical expression of the distributed energy system were summarized, and the trend of enrichment and diversification and the new characteristics of the system were evaluated. Then, the load forecasting technology was reviewed and analyzed from two aspects, fundamental research and application research. Research methods of the distributed energy system under the new trend of energies were discussed, and the boundaries of the broadened distributed energy technology were explored.
\end{abstract}

Keywords: distributed energy system; renewable energy; load forecasting; topological structure

\section{Introduction}

With the rapid development of the economy, global warming induced by the consumption of large amounts of fossil fuel has begun to threaten the ecological balance of the planet, which has caused every country all over the world to seek low-carbon energy systems. In September 2014, China published the National Plan on Climate Change, and proposed that in 2020, the non-fossil energy will account for $15 \%$ of the primary energy consumption [1]. In November 2014, the presidents of China and the U.S. issued a China-U.S. joint statement regarding the climate change, in which, the Chinese government promised that by around 2030 or earlier, $\mathrm{CO}_{2}$ emission would reach a peak value, nationwide $\mathrm{CO}_{2}$ emission per volume in 2030 would be reduced by $60-65 \%$ as compared to that in 2005, and non-fossil energies would account for $20 \%$ of the primary energy consumption [2].

Under the dual pressure of economic development and environmental protection, the cleaning and transforming of energy structure made the distributed energy system show some novel characteristics. First, the ratio of the renewable energy on the source side increases. The instability and discontinuity of renewable energy has a significant impact on the design and operation of distributed energy systems. Second, novel techniques such as electric power storage and thermal storage can be integrated on the supply side to a great extent. The utilization of these types of novel techniques enables the structure of distributed energy system on supply side to have certain differences from traditional combined cooling-heating-power (CCHP) systems. Third, the demand side would yield a certain level of diversification. Other than traditional demand for cooling, heating, and power, some parks and users may even have other demand elements, such as fresh water, carbon products, and clean air. In conclusion, the optimization and upgrade in some links related to the distributed energy system are urgently needed, such as design, application, and operation strategies, etc. 
In addition, President $\mathrm{Xi}$ emphasized that China supports the discussion of the establishment of a global energy network at the United Nations Sustainable Development Summit in September of 2015 [3]. Besides, some novel network side concepts, such as Energy Internet, Pan Energy Net, active distribution networks, and micro-grid, have been widely concerned under the background of the construction of global energy internet. In accordance with a new energy trend, issues like how the distributed energy system would find a position in the study of the future energy internet, and how novel techniques would be associated with the research system of traditional distributed energy, have become new research topics.

In summary, the current challenges faced by distributed energy fields can be summarized as follows: first, the topological structure of the distributed energy system tends to enrichment and diversification. Meanwhile, with the introduction of renewable energy, the distributed energy system would face challenges in various aspects of design, application, and operation. For example, the power fluctuation of photovoltaic, wind power, and other renewable energy has a great impact to the distributed energy system; many load-forecasting techniques are applied to renewable energy power generation forecasting. Second, the novel techniques strengthening the interconnection of different energy resources have developed rapidly under the background of energy internet. The distributed energy system is becoming a subsystem of the energy internet, thus some new technological features from energy internet are adopted by new type distributed energy systems, e.g., how to achieve the interconnection between the distributed energy, intelligent control based on information, and achieve energy efficient exchange of the entire network, are becoming new topics of distributed energy system to replace tradition research focus on energy-efficiency.

Finding a way to cope with these challenges via technical approaches has become a research hotspot in related fields over the past few years. This paper proceeds with one of these hot topics, concerning the operation optimization of the distributed energy system. Afterwards, as a key technique in the operation and optimization of the distributed energy system, the research and application of load forecasting is reviewed. Further, the integration of the load forecasting technology into the operation optimization of the distributed energy system was used as a case study to review the research methods in the distributed energy system in response to new trends in the energy field. The boundaries of the broadened distributed energy technology are further explored. The idea of this paper is to analyze the changes in the topological structure of the distributed energy system (distributed energy system topological structure is the composition and the structure of the distributed energy system), and then get the mathematical expression. Such development in the topological of distributed energy system further activated the research on Load forecasting, not only on power, but also on heating and cooling. Based on such motivation, trends in load forecasting is analyzed and summarized, as is one of the key technologies of distributed energy system optimization.

\section{Topological Structure and Mathematical Expressions of the Distributed Energy System}

\subsection{Topological Structure}

The changes in the topological structure of the distributed energy system are shown in Figure 1. PGU represents Power Generation Unit, and WHR represents Waste Heat Recovery. The left side represents the traditional distributed energy systems, which output cooling, heating, and power through combined cooling-heating-and-power. Besides, the right side is the current distributed energy systems, which contains more elements, its first column is the source side, the second column is the energy supply system, and the third column is the demand side. This means that the supply side includes not only traditional energy such as natural gas, but also renewable energy such as biomass and solar energy. Moreover, other than cooling, heating, and power, the demand side also includes fresh water and carbon products. The intermediate energy supply system also transforms from a single engine to an integration of multiple techniques (energy storage). The topological structure represents the changes of composition and structure of distributed energy system, it is the basis for researching 
the key technologies of distributed energy system (DES) operation optimization. Table 1 summarizes the research concerning the topological structure of the distributed energy system in recent years. It is clear that most research refers to renewable energy, and this feature is similar with the typical structure mentioned in a previous work [4]. All of the research takes energy storage into consideration, including power and heating, which can be clearly found in the typical structure as described in another previous work [5]; a typical supply side should at least include two types of energy product, which is apparently different from the structure of the traditional cooling-heating-power (CCHP) distributed energy system. Thus, the topological structure of the distributed energy system is the key to the rich and diversified trend of elements in the distributed energy system. In addition, the basic configuration and element expression of the topological structure has become an auxiliary expression tool commonly used in the study of the novel distributed energy system.

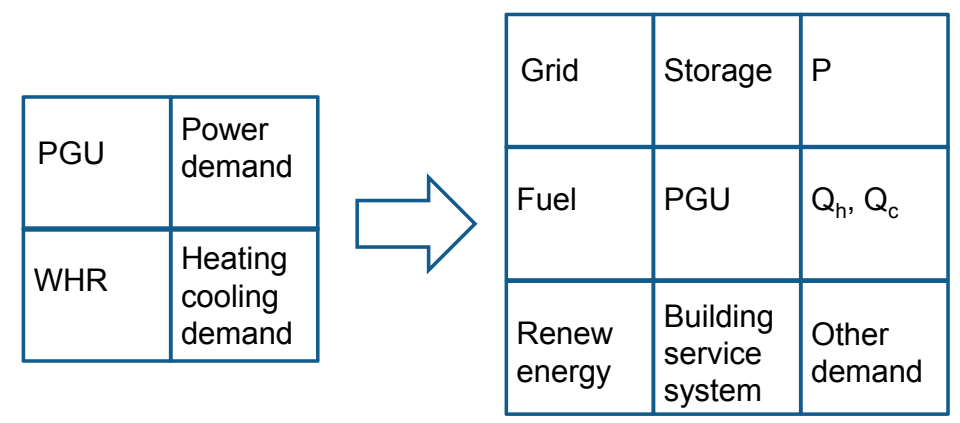

Figure 1. Evolution of distributed energy system topological structure.

Table 1. Research status of distributed energy system structure.

\begin{tabular}{|c|c|c|c|c|c|c|c|c|c|c|c|c|}
\hline \multirow[b]{2}{*}{ Year } & \multirow[b]{2}{*}{ Authors } & \multicolumn{3}{|c|}{ Source Side } & \multicolumn{3}{|c|}{ Supply Side } & \multicolumn{3}{|c|}{ Demand Side } & \multicolumn{2}{|c|}{ Spatial Scale } \\
\hline & & Gas & PV & $\begin{array}{c}\text { Electrical } \\
\text { Grid }\end{array}$ & CHP & $\begin{array}{c}\text { Electrical } \\
\text { Storage }\end{array}$ & $\begin{array}{l}\text { Heat } \\
\text { Storage }\end{array}$ & Cooling & Heating & Power & Community & $\begin{array}{l}\text { Family } \\
\text { House }\end{array}$ \\
\hline 2016 & $\begin{array}{l}\text { Molin } \\
\text { et al. [4] }\end{array}$ & & $\sqrt{ }$ & $\sqrt{ }$ & & $\sqrt{ }$ & & & & $\sqrt{ }$ & $\checkmark$ & \\
\hline 2016 & $\begin{array}{l}\text { Vaisanen } \\
\text { et al. [6] }\end{array}$ & & $\sqrt{ }$ & $\sqrt{ }$ & $\sqrt{ }$ & $\sqrt{ }$ & & & $\sqrt{ }$ & $\sqrt{ }$ & $\sqrt{ }$ & \\
\hline 2015 & $\begin{array}{l}\text { Guarino } \\
\text { et al. [7] }\end{array}$ & & $\sqrt{ }$ & $\sqrt{ }$ & & $\sqrt{ }$ & & & & $\sqrt{ }$ & & $\sqrt{ }$ \\
\hline 2015 & $\begin{array}{l}\text { Hirvonen } \\
\text { et al. [8] }\end{array}$ & & $\sqrt{ }$ & $\sqrt{ }$ & & $\sqrt{ }$ & & & & $\sqrt{ }$ & & $\sqrt{ }$ \\
\hline 2015 & $\begin{array}{l}\text { Alahäivälä } \\
\text { et al. [9] }\end{array}$ & $\sqrt{ }$ & & $\sqrt{ }$ & $\sqrt{ }$ & $\sqrt{ }$ & $\sqrt{ }$ & & $\sqrt{ }$ & $\sqrt{ }$ & & $\sqrt{ }$ \\
\hline 2014 & $\begin{array}{c}\text { Cao et al. } \\
\text { [5] }\end{array}$ & $\sqrt{ }$ & & $\sqrt{ }$ & $\sqrt{ }$ & $\sqrt{ }$ & $\sqrt{ }$ & & $\sqrt{ }$ & $\sqrt{ }$ & & $\sqrt{ }$ \\
\hline 2014 & $\begin{array}{l}\text { Cao et al. } \\
{[10]}\end{array}$ & & $\sqrt{ }$ & $\sqrt{ }$ & & $\sqrt{ }$ & & & & $\sqrt{ }$ & & $\sqrt{ }$ \\
\hline 2014 & $\begin{array}{l}\text { Mohamed } \\
\text { et al. [11] }\end{array}$ & $\sqrt{ }$ & $\sqrt{ }$ & $\sqrt{ }$ & $\sqrt{ }$ & $\sqrt{ }$ & $\sqrt{ }$ & & $\sqrt{ }$ & $\sqrt{ }$ & & $\sqrt{ }$ \\
\hline
\end{tabular}

\subsection{Mathematical Expression}

Matrix (1) describes energy balance in the traditional distributed energy system [12]. The left side of the equation describes the load side, and the right side describes the energy supply side.

$$
\underbrace{\left(\begin{array}{c}
L_{1} \\
L_{2} \\
\vdots \\
L_{m}
\end{array}\right)}_{L}=\underbrace{\left(\begin{array}{cccc}
c_{11} & c_{12} & \cdots & c_{1 n} \\
c_{21} & c_{22} & \cdots & c_{2 n} \\
\vdots & \vdots & \ddots & \vdots \\
c_{m 1} & c_{m 2} & \cdots & c_{m n}
\end{array}\right)}_{C} \underbrace{\left(\begin{array}{c}
P_{1} \\
P_{2} \\
\vdots \\
P_{n}
\end{array}\right)}_{P}
$$


Here, $L$ represents the building load, which includes building demands such as cooling, heating, and power, etc.; $P$ represents the energy supply, which includes traditional energy resources and renewable energy resources; $C$ is a performance parameter of the energy supply system, which is a matrix consisting of coefficients of the curves regarding the performance of each sub-system. With the development of distributed energy system (DES), there are more and more energy supply systems that transfer the energy from the source side to the demand side in DES, and different supply systems have different performance.

With the development of the distributed energy system, energy storage devices were developed, and matrix (2) describes the energy balance of the energy storage device in the distributed energy system.

$$
\underbrace{\left(\begin{array}{c}
M_{1} \\
M_{2} \\
\vdots \\
M_{m}
\end{array}\right)}_{M}=\underbrace{\left(\begin{array}{cccc}
s_{11} & s_{12} & \cdots & s_{1 n} \\
s_{21} & s_{22} & \cdots & s_{2 n} \\
\vdots & \vdots & \ddots & \vdots \\
s_{m 1} & s_{m 2} & \cdots & s_{m n}
\end{array}\right)}_{S} \underbrace{\left(\begin{array}{c}
A_{1} \\
A_{2} \\
\vdots \\
A_{n}
\end{array}\right)}_{A}
$$

Here, $M$ represents the energy output of the energy storage device; $A$ represents the energy storage supply, which includes energy storage such as cooling, heating and power; and, $S$ represents the performance parameter of the energy storage device, which is a matrix consisting of coefficients of curves regarding the performance of each sub-energy storage.

All links of the distributed energy system, including energy supply, transmission, and utilization, and can be expressed using matrix (3), the $L^{\prime}$ is supplied by two parts, one is traditional energy resources and renewable energy resources, another one is energy storage device.

$$
L^{\prime}=\left(\begin{array}{ll}
C & S
\end{array}\right) \cdot\left(\begin{array}{c}
P \\
A
\end{array}\right)
$$

Therefore, as a common mathematical tool used in the research field of the distributed energy, the mathematical expressions of matrices directly reflects the numeralization of the new characteristics in the distributed energy system.

\section{Load Forecasting}

Based on the determination of the change in the core spirit of the distributed energy system, this paper proceeds with the load forecasting technology to discuss changes in the broadening of the technical border of the distributed energy system and succeeding research methods in aspects like the optimization of the process after the new technology is integrated.

\subsection{Fundamental Research}

\subsubsection{Concept and Classification}

Load forecasting is used to predict load data at a specific moment in the future based on various factors, such as the operation characteristics, capacity expansion decisions, natural conditions, and social influences of the system when a certain amount of precision is needed [13]. It is considered an effective supporting method that complements decision-making, which can be used to adjust the energy supply system based on the load by changing the operation strategy.

Load forecasting can be divided into long-term, medium-term, and short-term load forecasting according to the length of the forecasting duration. Long-term load forecasting typically refers to forecasts made 1 to 10 years in advance, which is often used as a basis for the determination of future energy demand and planning policies. The medium-term load forecasting often refers to forecasts made for a few weeks to a few months in advance, which is used to guide planning in 
the companies. Short-time load forecasting includes forecasts made for a few hours to a few days in advance, which can be used to supervise the operation and control of the distributed energy system [14]. Further, the forecast algorithm can be a linear regression algorithm, a timing sequence analysis algorithm, an exponential smoothing algorithm, or an artificial neural network algorithm, etc. Typical studies on the load forecasting in recent years are summarized in Table 2 . With reference to review papers in a related research area published prior to 2015, it can be seen that the research in this field is expanding from pure electricity load forecasting towards the cooling and heating load forecasting $[15,16]$. More and more novel algorithms are established, and the research is transitioning towards the more challenging short-time forecast.

Table 2. Summary on load forecast research from exiting publications.

\begin{tabular}{|c|c|c|c|c|}
\hline Year & Author & Prediction Model & Load Type & Time Scale \\
\hline 2017 & Bianchi et al. [17] & Echo State Networks and PCA Decomposition & electricity & $10 \mathrm{~min}$ \\
\hline 2016 & Gupta et al. [18] & wavelet neural network & electricity & hour \\
\hline 2016 & Idowu et al. [19] & support vector machine & heating & hour \\
\hline 2016 & Deb et al. [20] & artificial neural network & cooling & day \\
\hline 2015 & Chitsaz et al. [21] & Self-Recurrent Wavelet Neural Network & electricity & hour \\
\hline 2015 & Protic et al. [22] & SVM-WAVELET & heating & hour \\
\hline 2015 & Abdoos et al. [23] & support vector machine & electricity & hour \\
\hline 2015 & Bianchi et al. [24] & Recurrent Neural Networks & $\begin{array}{l}\text { electricity } \\
\text { cooling }\end{array}$ & hour \\
\hline 2014 & Chou et al. [25] & SVM-ANN & $\begin{array}{c}\text { and } \\
\text { heating }\end{array}$ & hour \\
\hline 2014 & Rodrigues et al. [26] & artificial neural network & electricity & hour \\
\hline 2013 & Bacher et al. [27] & time-series & heating & hour \\
\hline 2012 & Ilić et al. [28] & artificial neural network & electricity & hour \\
\hline
\end{tabular}

\subsubsection{Research Methods}

The matrix (4) describes the major content of the research in load forecasting, the left side of the equation shows the load at the moment $t+1$, the $F$ matrix in the right side of the equation is a matrix of coefficients, and $L_{t}$ is the load at the moment $t$.

$$
\underbrace{\left(\begin{array}{c}
L_{t_{1}+1} \\
L_{t_{2}+1} \\
\vdots \\
L_{t_{m}+1}
\end{array}\right)}_{L_{t+1}}=\underbrace{\left(\begin{array}{cccc}
f_{11} & f_{12} & \cdots & f_{1 n} \\
f_{21} & f_{22} & \cdots & f_{2 n} \\
\vdots & \vdots & \ddots & \vdots \\
f_{m 1} & f_{m 2} & \cdots & f_{m n}
\end{array}\right)}_{F} \underbrace{\left(\begin{array}{c}
L_{t_{1}} \\
L_{t_{2}} \\
\vdots \\
L_{t_{m}}
\end{array}\right)}_{L_{t}}
$$

Here, $L$ represents the building load that includes the building demands of cooling, heating, power, etc.; $F$ represents the parameters of load influencing factors, which is a matrix consisting of influencing factors such as outdoor weather conditions, number of personnel, and holidays. Current research such as artificial neural networks and support vector machines both find the law of change in the historical load, and combined with weather and other factors. This matrix is combined with Equation (3) to revise the load matrix in the left side of the equation. Thus, as shown in Equations (5) and (6), they describe the role of load forecasting in distributed energy systems, which minimize the difference between supply and demand. With the introduction of renewable energy resources, the intermittent and unstable nature of renewable energy generation has a significant impact on the distributed energy system, so as shown in Equations (5) and (6), with the reduction in the duration of the forecast, the matching may be fulfilled in a smaller time scale, which approaches the ideal condition of instant matching.

$$
\min \Delta E=\int_{\tau_{1}}^{\tau_{2}} \Delta E d t
$$




$$
\Delta E=E_{\text {sup }}-E_{\text {dem }}=\left(\begin{array}{ll}
C & S
\end{array}\right)\left(\begin{array}{c}
P \\
A
\end{array}\right)-L
$$

In general, the research process of the application of load forecasting in distributed energy systems is often using the following steps: (1) data preparation, which includes data cleaning, data transformation, and data reduction; (2) data mining and modeling, which are performed by effectively supervising and studying the data, to establish the relationship between variables and the load; and, (3) error analysis, which through analyzing the error between the modeling forecast value and actual value, to establish the modification model and to improve precision of the model [29]. Afterward, the predicted error is determined based on the conditions of forecast and application, and an actual application is carried out after the conditions are satisfied. Otherwise, the process is modified from the step of data mining and modification, as shown in Figure 2.

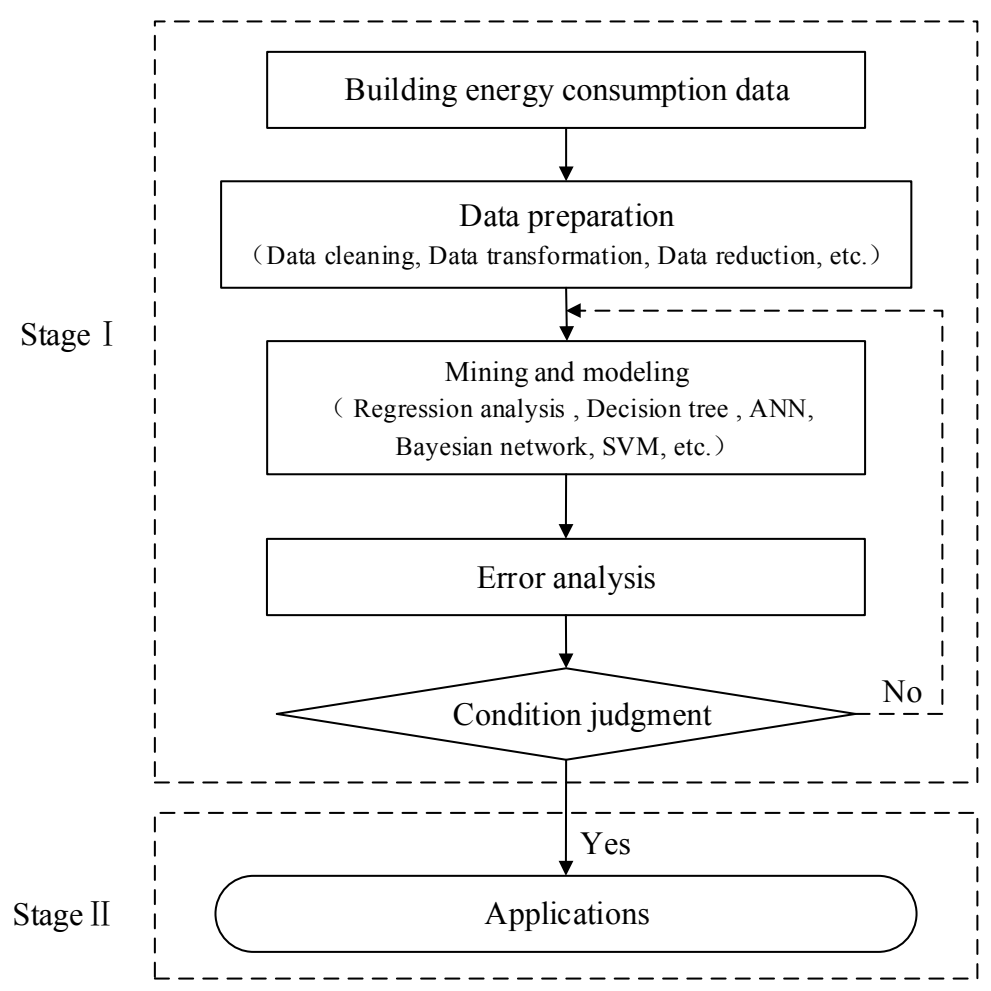

Figure 2. Flow chart of load forecasting.

\subsubsection{Current Research Progress}

In recent years, the application and study of the load forecasting in the field of distributed energy are quite active, which display significant interdisciplinary features. The constitution of the knowledge system of the application and studies is shown in Figure 3. This system comes primarily from three technical fields: study of data mining, model predictive control (MPC) in the control field, and the operation optimization field of machine group in building service systems, such as refrigeration and air conditioning. The area in which these three fields overlap enhances the rapid development of the load forecasting technique in the operation optimization of the distributed energy system. 


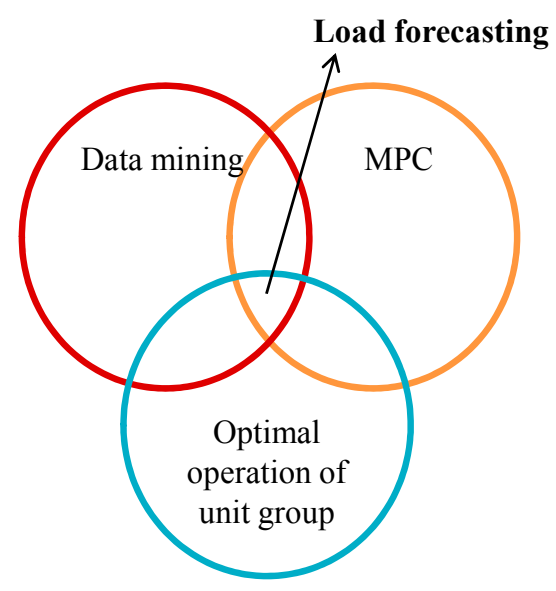

Figure 3. Load forecasting in cross disciplines.

Data mining is to a process by which useful knowledge can be extracted from a large amount of data, and the knowledge gleaned from data mining should be previously unknown and potential. The process of data mining is a complicated process which requires human-computer interaction, iterative adjustment, and progressive realization in order to discover high-quality knowledge [30]. It has been the most popular method of mining valuable information from historical data of power consumption of the building through data mining, analyze the operation conditions of the apparatus system of the building, and carry out load forecasting [31,32]. Machine learning is the core of artificial intelligence, which leads to the wide application in the field of artificial intelligence because it makes the computer intelligent. Machine learning such as artificial neural networks and support vector machine is often used for load forecasting $[19,20]$, which can greatly improve the prediction accuracy.

The model predictive control (MPC) is an advanced control technique based on modeling [33], and the algorithm of the model predictive control primarily has three key parts: predictive model, rolling optimization, and online correction [34]. In particular, the model predictive control has relatively low requirements regarding the model structure. As long as it can input the current and historical information of the object being controlled and output predictive information of the output object in a future duration, the predictive model can be used as the desired predictive model for the algorithm of model predictive control. A model predictive control (MPC) based coordinated operation framework for a grid-connected residential micro-grid with considering forecast errors is presented [35]. This residential micro-grid composes renewable energy (e.g., wind and solar) distributed generators (e.g., CHP), energy storages (e.g., battery bank and water tank), electrical vehicle, and smart loads (e.g., HVAC and washing machine). Simulation results show that the method is economic and flexible.

Buildings account for about a third of total energy consumption in global energy consumption, which comprises of residential and commercial buildings [36]. Besides, energy consumption of air conditioning accounts for a large part of the total energy consumption of buildings, reducing would play a decisive role in building energy efficiency [37]. Meanwhile, the central air conditioning system is often operated at a low load [38], so it has a certain guiding significance for optimization operation and power conservation of the buildings by virtue of the load forecasting. Macarthur et al. [39] proposed a prediction method for the air conditioning load of an ice storage system using a recursive autoregressive moving average model with external inputs, and achieve good results by optimizing controllers based on the prediction results.

\subsubsection{Development Trend}

In recent years, the development of the load forecasting technology in the field of optimization operation in distributed energy system has shown three new trends: 1 . the operation of such systems has been shown to be closely related to both climate and human activity, so hybrid forecasts based on 
climate and human behavior is a developing trend that may become more pronounced in the future; 2 . unlike in physical models (which is based on the basic principle of heat transfer, it is used to describe the load characteristic of building. Unlike to load forecasting on power, research methodology relies more on a physical model, rather than data-driven model, It is one of the trends that is expected to develop in the future to improve the coverage of spatial dimensions by the load forecasting, and reduce the time dimension via data driving and the cloud technology, which often performs forecasting by studying a large amount of the monitoring data, carrying out iterative calculations for multiple times, and establishing the mathematical model; 3 . the forecast is not only specific to the traditional load, but also covers gas load, electric vehicle charging load, renewable energy generation systems such as photovoltaic and wind power, and pollutant emission, which realizes the comprehensive forecast and operation of the multi-energy system. Renewable energy generation and load forecasting have something different, the cooling, heating, and power load of building has a certain regularity, but the regularity of renewable energy power generation such as photovoltaic and wind power is not strong, so renewable energy generation forecasting is more difficult than load forecasting.

Based on these three factors, scholars from the Massachusetts Institute of Technology proposed the concept of an energy box [40], which was used in the distributed energy system with the individual household as the unit. Further, this system included household appliances such as air conditioners, TVs, and dishwashers as well as roof ventilators, photovoltaic panels, electricity supplies, and batteries. Moreover, the energy box helped the system reach a supply-demand equilibrium by power generation forecasting of renewable energy in the system, such as wind power and photovoltaic energy. Besides, the energy box also takes into consideration the fluctuation of electricity prices and human preferences, to optimize the operation of the system and achieve the goal of improving economic efficiency and human comfort. In this way, forecasting the power generation of renewable energy would become a key point in future research, and its precise forecasting of power generation may solve issues regarding instability and discontinuity of renewable energy effectively. Thus, the combination of load forecasting and power generation forecasting of the renewable energy may lead to the enriched and diversified distributed energy systems.

\subsection{Application Research}

\subsubsection{Current Conditions}

In the real-world electrical infrastructure, actual system operators already have utilized load forecasting technology. However, application field of load forecasting is limited, only in large-scale energy systems. Currently, application research into the load forecasting in the distributed energy system is subject to factors such as the high cost of regulation and control, and thus is still in its initial stage. Existing representative findings are shown in Table 3, while most research remains in stage I, as shown in Figure 2, and few studies reach stage II.

Nikolaos et al. proposed an algorithm that aims to provide more heat energy to the difficult consumers when they need it the most [41]. The required input information are the short term weather forecast, and the supply hot water temperature propagation delays of the district heating grid as a function of the grid load level and consumption profiles. The methodology has been applied in a simplified case study of a $120 \mathrm{MW}$ district heating grid. The results showed that when compared to simple reactive and constant temperature control strategies, the performance of the grid in terms of minimum pressure difference at the consumers over a year was significantly better using the proposed proactive algorithm within a specific supply water temperature range. Chen et al. proposed an active control strategy of the micro-grid energy storage system based on short-term load forecast [42], when performing short-time forecast of the load in the micro-grid, this strategy would actively control the charging and discharging of the storage system, optimize the load curve of the micro-grid, and realize peak load shifting by considering capacity, charging-discharging characteristics, and limitations in the charging-discharging numbers of the batteries. Thus, the stable operation of 
the distributed power source can be ensured, and the electric energy quality of the micro-grid can be improved.

Table 3. Current situation of research and application of load forecasting.

\begin{tabular}{|c|c|c|c|c|c|c|}
\hline \multirow{2}{*}{ Year } & \multirow{2}{*}{ Authors } & \multirow{2}{*}{$\begin{array}{c}\text { Accuracy } \\
\text { (MAPE) }\end{array}$} & \multirow{2}{*}{ Load Type } & \multirow{2}{*}{ Purpose } & \multicolumn{2}{|c|}{ Stage } \\
\hline & & & & & I & II \\
\hline 2016 & Li et al. [43] & $3.43 \%$ & electricity & save electricity & $\sqrt{ }$ & \\
\hline 2016 & Fang et al. [44] & $8.40 \%$ & heating & energy conservation & $\sqrt{ }$ & \\
\hline 2016 & Nikolaos et al. [41] & - & heating & energy conservation & & $\sqrt{ }$ \\
\hline 2015 & Lee et al. [45] & $2.61 \%$ & electricity & save electricity & $\sqrt{ }$ & \\
\hline 2015 & A. Lahouar et al. [46] & $2.30 \%$ & electricity & save electricity & $\sqrt{ }$ & \\
\hline 2015 & Lou et al. [47] & $4.56 \%$ & electricity & save electricity & $\sqrt{ }$ & \\
\hline 2014 & A. Vaghefi et al. [48] & $3.10 \%$ & $\begin{array}{l}\text { electricity and } \\
\text { cooling }\end{array}$ & save electricity & $\sqrt{ }$ & \\
\hline 2015 & Qiao et al. [49] & $2.59 \%$ & gas & energy conservation & $\sqrt{ }$ & \\
\hline 2014 & Amini et al. [50] & $1.44 \%$ & electric vehicle & $\begin{array}{c}\text { Reduce the pressure } \\
\text { of the grid }\end{array}$ & $\sqrt{ }$ & \\
\hline 2011 & Chen et al. [42] & - & electricity & $\begin{array}{l}\text { improve power } \\
\text { quality of micro-grid }\end{array}$ & & $\sqrt{ }$ \\
\hline
\end{tabular}

\subsubsection{Existing Cases}

The project of No. 2 energy station in Sino-Singapore Tianjin Eco-city is a typical case in that the optimization scheduling of the operation was carried out based on the load forecasting results. It primarily pre-determined the load using weather forecast data, and the load forecasting model is shown in Figure 4. Based on data such as the historical load, environmental temperature, weather conditions, and type of day, the load predictive model was established to obtain the load values in the future $24 \mathrm{~h}$. Moreover, the distributed energy system is shown in Figure 5, which consists of combined cooling-heating-and-power (CCHP), ground source heat pump machine group, electric chillers, and energy storage device. The load values in the future $24 \mathrm{~h}$ were entered into the operation platform in the energy station based on weather forecasts. Further, the platform controlled and adjusted related machine group according to the results of load forecasting to achieve optimize operation of the system. The successful demonstration of the related research results proves the feasibility of the application of load forecasting technology in the distributed energy system.

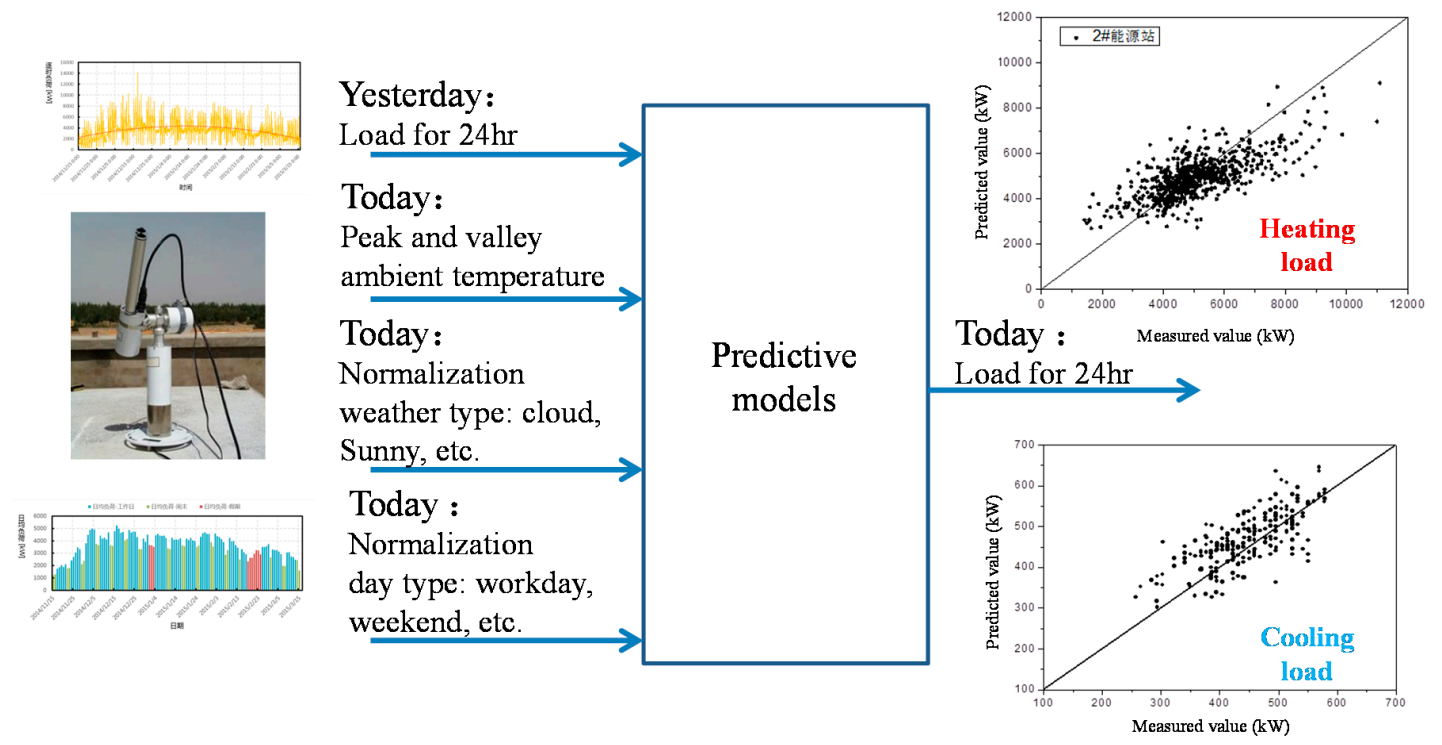

Figure 4. Model for the load forecasting. 


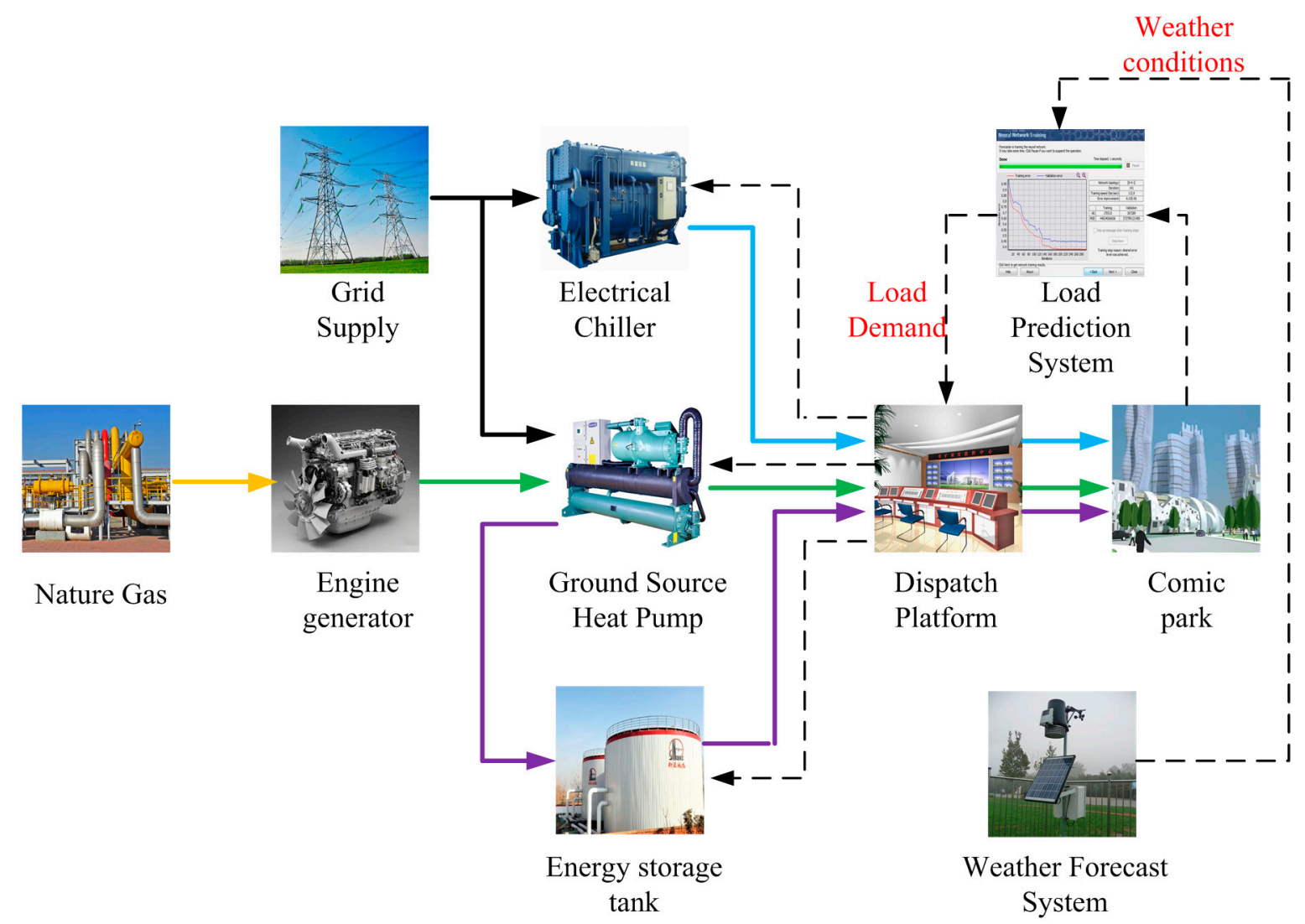

Figure 5. The system structure diagram of the No. 2 energy station in Sino-Singapore Tianjin Eco-city.

\subsubsection{Development Trend}

When it comes to practice application, future work on load forecasting may focus on the following factors. First, the short-time and high-precision technical solutions would be developed based on weather data, and extend its application scope to the community or city level. Second, the development of products combines the energy storage and the distributed energy to produce a set of products that integrates the operation optimization strategy. Third, the government may guide the development and establishment of the energy system scheduling platform, by means of several methods including load and energy supply forecast, system simulation, optimization analysis, and exemplary application, and even establish an interconnection center based on specific cities.

\section{Conclusions}

The topological structure of the distributed energy system has changed considerably, and with the introduction of the renewable energy resources, distributed energy systems are in urgent need of updating in the aspects of design, application, and operation strategy. This paper concludes and analyzes the load forecast in the key technique of the operation optimization of the distributed energy system from two aspects regarding the fundamental research and application research, and the following conclusions are obtained:

(1) The load forecasting can be used to adjust the supply of the energy system, and the load can be precisely adjusted by changing the operation strategy. However, current studies on the load forecasting mostly remain at the theoretical stage and lack of experimental research, which indicates that there is still a relatively long way to go before the large-scale utilization of the load forecasting technique is achieved. By integrating big data and the cloud storage technology, not only the traditional cooling-heating-and-power load can be predicted, but comprehensive 
forecasting of multi-energy systems such as the gas load and electric vehicle charging and discharging load can also be realized. Further, by combining the power generation forecast of the renewable energy resources with the big data and the cloud storage technology, the renewable energies may be utilized to their full extent.

(2) Most research regarding the load forecasting remains in the stage of algorithm optimization and precision improvement, and there is much more work to do in order to apply the predictive model in actual systems. For this reason, future work should focus on the development of technical solutions and products. The government may guide and initiate their use to increase the impact of load forecasting, thus the distributed energy system can be better developed.

Acknowledgments: This study was financially supported by National High-Technology Research and Development Program (“863" program) of China under Grant number 2015AA050403.

Author Contributions: Pengwei Su and Xue Tian have the same contribution to this paper, they took care of the literature review and wrote this paper; Yan Wang Sorted and compare the literature; Shuai Deng designed the paper; Jun Zhao provided the background; Qingsong An and Yongzhen Wang supervised the paper writing.

Conflicts of Interest: The authors declare no conflict of interest.

\section{References}

1. The Sate Council of China: Strategic Action Plan for Energy Development (2014-2020). Available online: http:/ / www.gov.cn/zhengce/content/2014-11/19/content_9222.htm (accessed on 7 June 2014).

2. China: Enhanced Actions on Climate Change-China's Intended Nationally Determined Contributions. Available online: http://www.sdpc.gov.cn/xwzx/xwfb/201506/t20150630_710204.html (accessed on 30 June 2015).

3. Xi, J. Seek common and sustainable development to do cooperation and win-win partnership. In Proceedings of the United Nations Development Summit, New York, NY, USA, 26 September 2015.

4. Molin, A.; Schneider, S.; Rohdin, P. Assessing a regional building applied PV potential—Spatial and dynamic analysis of supply and load matching. Renew. Energy 2016, 91, 261-274. [CrossRef]

5. Cao, S.; Mohamed, A.; Hasan, A. Energy matching analysis of on-site micro-cogeneration for a single-family house with thermal and electrical tracking strategies. Energy Build. 2014, 68, 351-363. [CrossRef]

6. Väisänen, S.; Mikkilä, M.; Havukainen, J. Using a multi-method approach for decision-making about a sustainable local distributed energy system: A case study from Finland. J. Clean. Prod. 2016, 137, 1330-1338. [CrossRef]

7. Guarino, F.; Cassarà, P.; Longo, S. Load match optimisation of a residential building case study: A cross-entropy based electricity storage sizing algorithm. Appl. Energy 2015, 154, 380-391. [CrossRef]

8. Hirvonen, J.; Kayo, G.; Cao, S. Renewable energy production support schemes for residential-scale solar photovoltaic systems in Nordic conditions. Energy Policy 2015, 79, 72-86. [CrossRef]

9. Alahäivälä, A.; Heß, T.; Cao, S. Analyzing the optimal coordination of a residential micro-CHP system with a power sink. Appl. Energy 2015, 149, 326-337. [CrossRef]

10. Cao, S.; Kai, S. Impact of simulation time-resolution on the matching of PV production and household electric demand. Appl. Energy 2014, 128, 192-208. [CrossRef]

11. Mohamed, A.; Cao, S.; Hasan, A. Selection of micro-cogeneration for net zero energy buildings (NZEB) using weighted energy matching index. Energy Build. 2014, 80, 490-503. [CrossRef]

12. Ahčin, P.; Šikić, M. Simulating demand response and energy storage in energy distribution systems. In Proceedings of the IEEE International Conference on Power System Technology, Hangzhou, China, 24-28 October 2010; pp. 1-7.

13. Liao, N. Review of the short-term load forecasting methods of electric power system. Power Syst. Prot. Control 2011, 39, 147-152. (In Chinese)

14. Raza, M.Q.; Khosravi, A. A review on artificial intelligence based load demand forecasting techniques for smart grid and buildings. Renew. Sustain. Energy Rev. 2015, 50, 1352-1372. [CrossRef]

15. Singh, A.K.; Ibraheem, I.; Khatoon, S. Load forecasting techniques and methodologies: A review. In Proceedings of the International Conference on Power, Control and Embedded Systems, Allahabad, India, 17-19 December 2012; pp. 1-10. 
16. Powell, K.M.; Sriprasad, A.; Cole, W.J. Heating, cooling, and electrical load forecasting for a large-scale district energy system. Energy 2014, 74, 877-885. [CrossRef]

17. Bianchi, F.M.; Maiorino, E.; Kampffmeyer, M.C.; Rizzi, A.; Jenssen, R. An overview and comparative analysis of Recurrent Neural Networks for Short Term Load Forecasting. arXiv, 2017, arXiv:1705.04378.

18. Gupta, S.; Singh, V.; Mittal, A.P. Weekly Load Prediction Using Wavelet Neural Network Approach. In Proceedings of the Second International Conference on Computational Intelligence \& Communication Technology, Odisha, India, 12-13 February 2016; pp. 174-179.

19. Idowu, S.; Saguna, S.; Åhlund, C. Applied Machine Learning: Forecasting Heat Load in District Heating System. Energy Build. 2016, 133, 478-488. [CrossRef]

20. Deb, C.; Eang, L.S.; Yang, J. Forecasting diurnal cooling energy load for institutional buildings using Artificial Neural Networks. Energy Build. 2016, 121, 284-297. [CrossRef]

21. Chitsaz, H.; Shaker, H.; Zareipour, H. Short-term electricity load forecasting of buildings in micro grids. Energy Build. 2015, 99, 50-60. [CrossRef]

22. Protić, M.; Shahaboddin, S. Forecasting of consumers heat load in district heating systems using the support vector machine with a discrete wavelet transform algorithm. Energy 2015, 87, 343-351. [CrossRef]

23. Rodrigues, F.; Cardeira, C.; Calado, J.M. The Daily and Hourly Energy Consumption and Load Forecasting Using Artificial Neural Network Method: A Case Study Using a Set of 93 Households in Portugal. Energy Procedia 2014, 62, 220-229. [CrossRef]

24. Bianchi, F.M.; De Santis, E.; Rizzi, A.; Sadeghian, A. Short-term electric load forecasting using echo state networks and PCA decomposition. IEEE Access 2015, 3, 1931-1943. [CrossRef]

25. Chou, J.S.; Bui, D.K. Modeling heating and cooling loads by artificial intelligence for energy-efficient building design. Energy Build. 2014, 82, 437-446. [CrossRef]

26. Abdoos, A.; Hemmati, M.; Abdoos, A. Short term load forecasting using a hybrid intelligent method. Knowl.-Based Syst. 2015, 76, 139-147. [CrossRef]

27. Bacher, P.; Madsen, H.; Nielsen, H.A. Online short-term heat load forecasting for single family houses. Energy Build. 2013, 65, 5741-5746. [CrossRef]

28. Ilić, S.; Selakov, A.; Vukmirović, S. Short-term load forecasting in large scale electrical utility using artificial neural network. J. Sci. Res. 2013, 72, 739-745.

29. Zhang, L.; Yang, T.; Xiao, G. MATLAB Data Analysis and Data Mining; Machine Press: Beijing, China, 2015. (In Chinese)

30. Tsai, C.F.; Lin, W.C.; Ke, S.W. Big Data Mining with Parallel Computing: A Comparison of Distributed and MapReduce Methodologies. J. Syst. Softw. 2016, 122, 83-92. [CrossRef]

31. Cheng, F.; Fu, X.; Wang, S. Development of prediction models for next-day building energy consumption and peak power demand using data mining techniques. Appl. Energy 2014, 127, 1-10.

32. Fan, C.; Xiao, F.; Yan, C. A framework for knowledge discovery in massive building automation data and its application in building diagnostics. Autom. Constr. 2015, 50, 81-90. [CrossRef]

33. Xu, J.; Boom, T.V.; Schutter, B.D. Optimistic optimization for model predictive control of max-plus linear systems. Automatica 2016, 74, 16-22. [CrossRef]

34. Camacho, E.F.; Bordons, C. Model Predictive Control; Springer: Berlin, Germany, 2004.

35. Zhang, Y.; Zhang, T.; Wang, R. Optimal operation of a smart residential micro-grid based on model predictive control by considering uncertainties and storage impacts. Sol. Energy 2015, 122, 1052-1065. [CrossRef]

36. International Energy Agency. Buildings Overview in: Transition to Sustainable Buildings; IEA Publications: Paris, France, 2013; p. 26.

37. Sayaka, K.; Daisaku, N.; Saburo, M. Analysis of energy consumption of room air conditioners: An approach using individual operation data from field measurements. Appl. Therm. Eng. 2017, 112, 7-14.

38. Yeung, T.M. Performance Evaluation of Hotel Chiller Plant, Research Project: 3103; The Hong Kong Polytechnic University: Hong Kong, China, 2000.

39. Macarthur, J.W.; Mathur, A.; Zhao, J. On-Line Recursive Estimation for Load Profile Prediction. ASHRAE Trans. 1989, 95, 621-628.

40. Livengood, D.J. The Energy Box: Comparing Locally Automated Control Strategies of Residential Electricity Consumption under Uncertainty; Massachusetts Institute of Technology: Cambridge, MA, USA, 2012. 
41. Papakonstantinou, N.; Savolainen, J.; Koistinen, J. District heating temperature control algorithm based on short term weather forecast and consumption predictions. In Proceedings of the IEEE International Conference on Emerging Technologies and Factory Automation, Berlin, Germany, 6-9 September 2016.

42. Chen, Y.; Zhang, B.; Wang, J. Active control strategy for micro-grid energy storage system based on short-term load forecasting. Power Syst. Technol. 2011, 35, 35-40. (In Chinese)

43. Li, S.; Goel, L.; Wang, P. An ensemble approach for short-term load forecasting by extreme learning machine. Appl. Energy 2016, 170, 22-29. [CrossRef]

44. Fang, T.; Lahdelma, R. Evaluation of a multiple linear regression model and SARIMA model in forecasting heat demand for district heating system. Appl. Energy 2016, 179, 544-552. [CrossRef]

45. Lee, W.J.; Hong, J. A hybrid dynamic and fuzzy time series model for mid-term power load forecasting. Int. J. Electr. Power Energy Syst. 2015, 64, 1057-1062. [CrossRef]

46. Lahouar, A.; Slama, J.B. Day-ahead load forecast using random forest and expert input selection. Energy Convers. Manag. 2015, 103, 1040-1051. [CrossRef]

47. Lou, C.W.; Dong, M.C. A novel random fuzzy neural networks for tackling uncertainties of electric load forecasting. Int. J. Electr. Power Energy Syst. 2015, 73, 34-44. [CrossRef]

48. Vaghefi, A. Modeling and forecasting of cooling and electricity load demand. Appl. Energy 2014, 136, $186-196$. [CrossRef]

49. Qiao, W.; Chen, B. Hourly load prediction for natural gas based on Haar wavelet tansforming and ARIMA-RBF. J. Petrochem. Univ. 2015, 28, 75-80.

50. Amini, M.H.; Kargarian, A.; Karabasoglu, O. ARIMA-based decoupled time series forecasting of electric vehicle charging demand for stochastic power system operation. Electr. Power Syst. Res. 2016, 140, 378-390. [CrossRef]

(C) 2017 by the authors. Licensee MDPI, Basel, Switzerland. This article is an open access article distributed under the terms and conditions of the Creative Commons Attribution (CC BY) license (http://creativecommons.org/licenses/by/4.0/). 